\title{
A COMBINED METHOD FOR RELIABILITY ANALYSIS OF MULTI-STATE SYSTEM OF MINOR-REPAIRABLE COMPONENTS
}

\section{ŁĄCZONA METODA ANALIZY NIEZAWODNOŚCI SYSTEMU WIELOSTANOWEGO SKŁADAJĄCEGO SIĘ Z ELEMENTÓW PODLEGAJĄCYCH DROBNEJ NAPRAWIE}

\begin{abstract}
This paper discusses the multi-state system (MSS) consisted of multi-state components with minor failure and minor repair. In order to obtain the reliability indices of MSS, a new combined method is suggested. This method is based on the Markov stochastic process and the universal generating function (UGF) technology. The traditional idea of modeling the MSS is to use straightforward Markov process. That is not effective enough for the MSS because the model of the system is complicated usually and the state space often arouses "dimension curse" - huge numbers of the states. We suggest it should model the multi-state components and the UGF of multi-state components can be obtained firstly. Then the MSS can be decomposed into several subsystems which only contain simple series-parallel structure. According to the physical nature of the subsystems, the UGF of those subsystems can be employed recursively. Furthermore the UGF of the entire MSS will be obtained. Therefore, the reliability indices of the MSS can be evaluated easily. The suggested method simplifies greatly the complexity of calculation and is well formulized. Two numerical examples illustrate this method.
\end{abstract}

Keywords: multi-state system, reliability index, Markov stochastic process, universal generating function, minor repair.

\begin{abstract}
$W$ artykule omówiono system wielostanowy (multi-state system, MSS) skladajacy się z elementów wielostanowych, które moga ulegać drobnym uszkodzeniom i podlegaja drobnym naprawom. Zaproponowano nowa metode taczona, która pozwala wyznaczać wskaźniki niezawodności MSS. Metoda ta opiera się na procesie stochastycznym Markowa oraz technologii uniwersalnej funkcji tworzacej (universal generating function, UGF). Tradycyjnie do modelowania MSS wykorzystuje się sam proces Markowa. Metoda ta nie jest jednak wystarczająco skuteczna w przypadku MSS, ponieważ modele tego typu systemów są zazwyczaj skomplikowane, a przestrzeń stanów często prowadzi do tzw. "przekleństwa wielowymiarowości" - konieczności uwzględnienia ogromnej liczby stanów. Nasza metoda polega na modelowaniu elementów wielostanowych, dla których, w pierwszej kolejności wyznacza się UGF. Następnie MSS można rozłożyć na kilka podsystemów, które maja prostą strukturę szeregowo-równoległa. Charakter fizyczny tych podsystemów, pozwala na rekurencyjne stosowanie UGF dla tych podsystemów. Ponadto metoda umożliwia wyznaczenie UGF dla catego MSS, co pozwala na łatwą ocenę wskaźników niezawodności MSS. Proponowana metoda znacznie upraszcza obliczenia $i$ jest dobrze sformalizowana. W pracy przedstawiono dwa przyktady numeryczne, które ilustrują omawiana metodę.
\end{abstract}

Stowa kluczowe: system wielostanowy, wskaźnik niezawodności, proces stochastyczny Markowa, uniwersalna funkcja tworzaca, drobne naprawy.

\section{Introduction}

The classical reliability principles allow that a system and/or a component can only have two functional states, perfect functionality and complete failure. Numerous research efforts have been devoted to binary-state reliability theory, modeling, indices analysis and calculation etc $[6,5,35,4,33]$. However, those theories and assumptions are oversimplified for the realistic situations. In addition to the two states mentioned above, many complicated systems and/or their constitutive components have several intermediate states typically in real world. For example, the manufacturing, production, power generation and oil and/or gas transportation systems, whose overall performance can be settled on different levels ( e.g. $100 \%, 80 \%, 50 \%$ of the nominal capacity), depending on their operating conditions of their constitutive multi-state elements $[12,31,24,34,44,9]$. These phenomena make it cumbersome to suffice increasingly stringent requirements for accurate reliability assessment using traditional binary reliabil- ity methods. Therefore, the reliability theories for multi-state system (MSS) have been impelled strongly.

The early research in MSS had been focused on the extensions of binary-state components and coherent systems. The generalization of binary coherent systems had been developed early for multi-state components by Barlow and $\mathrm{Wu}$ [7]. The widespread recognition of MSS is that it has been defined as having different performance levels and/or some failure modes with corresponding effects on the system's entire performance. Many researchers have made various contributions for the MSS reliability evaluation and modeling theory recently $[13,23,8,9,27,40]$. The commonly adopted methods have five basic approaches, such as, an extension of binary theory to MSS cases, the stochastic process approach, the universal generating function (UGF), the Monte-Carlo simulation and recursive algorithm etc $[14,45,22,19,2$, $20,37]$. The recent advances in MSS reliability theory have been collected in [1]. 
The modern stochastic process theory provides an advanced probabilistic framework which allows one to do many thing, just to name a few, to formulate the general failure models for the real systems, to obtain explicit formulas of various reliability indices for calculation, and to determine the optimal maintenance plans in complex situation etc. $[3,29,24,34,2]$. Especially the random process methods are often suggested to evaluate its reliability for a MSS with repairable components. Based on these methods, the state-space diagram of an MSS should be constructed firstly and then the transitions between all the states should be also determined subsequently. Usually the evolution process of a system can be represented by a continuous-time discrete state random process.

Usually, when the number of the system state is not too large, the mentioned above can be adopted directly. However, for the realistic engineering system, the straightforward using of random process for MSS reliability assessment is very difficult due to the "dimension explosion" - herds of system states. In order to formalize the analysis of MSS, considering a system made up of $n$ different repairable components. Each component $i$ has $m_{i}+1$ different performance levels, $i=1,2, \ldots, n$, such that the system is characterized by a state set of $M_{\text {sys }}=\prod_{i=1}^{n}\left(m_{i}+1\right)$. The value of $M_{\text {sys }}$ may be very huge even for a relative small MSS. For example, the maintenance strategies optimization of series-parallel systems often is involved in the combination of the component-level maintenance strategies. As the MSS described in [42], there are more than six millionaire possible combinations for multi-state component replacement strategy even though the system has only 4 subsystems and 14 components with less than 5 degradation states for each component. According to the maintenance strategy structure considered in [43], the size of the system-level strategy space will be also able to reach more than 100 million which is too large to be processed by the general enumeration method, where the system contains only 6 subsystems and 21 components with not more than 6 states. This "combinatorial explosion" situation can be also encountered in $[41,11,38]$ etc.

In addition, for a MSS the drawing of state-space diagram or modeling of construction is also a trivial work because non-formularized process may bring numerous mistakes even for a moderate scale MSS. The correct identification for all of the states and the transitions between states are also not a simple assignment. At the same time the current available computer resources may limit the feasibility of solving a model of hundreds of state equations.

In order to reduce the computational complexity of MSS, the UGF method, which had been proven to be very effective for high-dimension combinational problems, was introduced primarily by Ushakov [36]. A comprehensive up-to-date representation of UGF with many technical applications and its mathematical foundations can be found in [16]. A novel algorithm based on this technology had been developed for the reliability evaluation of an acyclic multi-state-node network system in [39]. It has also been extended in various fields such as the applications of fuzzy set theory, reliability redundancy optimal problem, maintenance decision-making etc resorting to its straightforward properties [10, 26, 28, 21]. The MSS performance distribution can be determined by the using of UGF method. The output performance levels of an MSS with series, parallel, series-parallel and bridge structure were evaluated in $[18,17,25,30,32,38]$ by the defined different composition operators.

Our contributions are as follows. We focus on the problem of evaluating the reliability and performance level of MSS consisted of repairable elements with statistically independent and with given failure probabilities. Considering the complexity of state and computation, the method's development may be extremely appealed to reliability engineers. The suggested approach is based on the stochastic process and UGF with the combination of block diagram method.[15].

\section{Stochastic process for MSS}

\subsection{Model for the MSS}

For the purpose of modeling an MSS, the characteristics of its elements need to be first defined. Generally speaking, any elements $i$ in MSS can have $m_{i}+1$ different states corresponding to the performance levels which can be represented by the set:

$$
\mathbf{g}_{i}=\left\{g_{i 0}, g_{i 1}, \cdots, g_{i m_{i}}\right\}
$$

where: $g_{i s}$ is the performance level of element $i$ in the state $s$, $s \in\left\{0,1, \cdots, m_{i}\right\}$. The current performance level $G_{i}$ of element $i$ at any instant time is a discrete random variable that takes value from $\mathbf{g}_{i}: G_{i} \in \mathbf{g}_{i}$. The probabilities of each different state or performance level for element $i$ can be denoted by the set:

$$
\mathbf{p}_{i}=\left\{p_{i 0}, p_{i 1}, \cdots, p_{i m_{i}}\right\}
$$

where:

$$
p_{i s}=\operatorname{Pr}\left\{G_{i}=g_{i s}\right\}
$$

Furthermore, one element's entire states composed a complete group are mutually exclusive event. That is to say, the element $i$ will be always in one and only one of $m_{i}+1$ states, such that:

$$
\sum_{s=0}^{m_{i}} p_{i s}=1
$$

Actually, eq. (3) defines the probability mass function ( $\mathrm{pmf}$ ) of the random variable $G_{i}$. The performance level distribution of element $i$ will be determined completely by the collection of pairs:

$$
C P_{i}=\left(g_{i s}, p_{i s}\right), s=0,1, \cdots, m_{i} \text {. }
$$

The system elements have certain performance levels corresponding to their respective states at one instant time. The modeling of an

MSS performance level is totally determined by the $C P_{i}, i=1,2, \cdots n$ when some external factors such as human incorrect operation, environmental effect etc, are out of consideration. Therefore, the states of an MSS are determined totally by the states of its components. Suppose the MSS has $k+1$ different states and the performance level corresponding to one state of the MSS at certain moment can be represented by $v_{j}, j=0,1, \cdots, k$. The MSS performance level is a random variable denoted by $V$ that takes values from the set:

$$
V=\left\{v_{0}, v_{1}, \cdots, v_{k}\right\} .
$$

The pmf of the MSS performance levels can be obtained in the following form:

$$
q_{j}=\operatorname{Pr}\left\{V=v_{j}\right\}, j=0,1, \cdots, k
$$


Using Cartesian product, we can define the space of all possible combinations of performance levels for all of system components as:

$$
C^{n}=\prod_{i=1}^{n}\left\{g_{i 0}, g_{i 1}, \cdots, g_{i m_{i}}\right\}
$$

The MSS system structure function is naturally introduced as:

$$
\Phi\left(G_{1}, G_{2}, \cdots, G_{n}\right): C^{n} \rightarrow V
$$

whose function is to map the space of the component's performance levels into the space of performance levels of MSS.

From the analysis mentioned above, the model of MSS includes two parts: one is the pmf of performance levels for all of the components, and the other is the structure function of the system. They can be rewritten as the following:

$$
\left\{\begin{array}{l}
\mathbf{g}_{i}, \mathbf{p}_{i}, 0 \leq i \leq n \\
V=\Phi\left(G_{1}, \cdots G_{n}\right)
\end{array}\right.
$$

\subsection{Repairable model for multi-state component}

One pervasive situation for a multi-state component is that it has a degradation (wear-out) and opposite (repairing) process. Without the loss of generality, the two processes can be defined as minor failures and minor repairs. For the multi-state component $i$ there is a performance level $g_{i s}$ corresponding to every state $s$. Those states will be ordered by performance level so that $g_{i s} \leq g_{i s+1}$ for any state $s$. The minor failures cause state transition only from $s$ to an adjacent state $s-1$ where $1 \leq s \leq m_{i}$. Conversely the minor repairs can only lead to the state transition from $s$ to an adjacent state $s+1$ where $0 \leq s \leq m_{i}-1$. That is to say, the component in the state $s$ will be in transition to $s-1$ if failure occurs and if repair has been accomplished the component in the state $s$ will transit to $s+1$. The special case is that in the state 0 it can only be repaired and transit to the state 1 and in the state $m_{i}$ it can only degrade to state $m_{i}-1$. The state transition diagram of component $i$ with minor failure and minor repair has been presented in Fig.1.

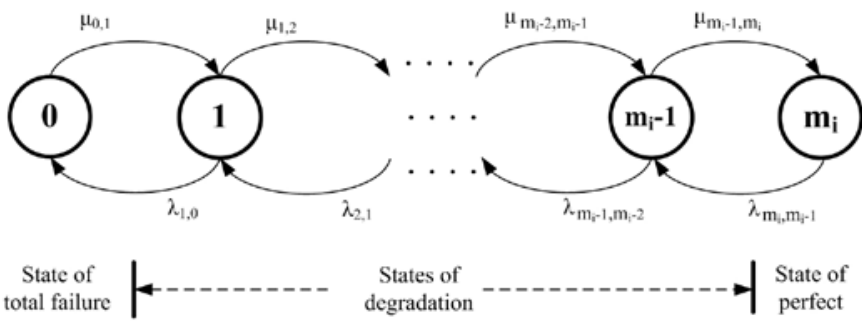

Fig. 1. State transition diagram of multi-state component $i$ with minor failure and minor repair

For a multi-state component its performance transition process will have Markov property and can be modeled as a Markov stochastic process if all its failure and repair times are exponential distribution. For a Markov stochastic process, each state transition has its own transition probability density. As represented in Fig.1, the failure rate $\lambda_{1,0}$ denotes the transition probability density from state 1 to state 0 because of minor failure and the repair rate $\mu_{0,1}$ indicates the corresponding transition intensity from state 0 to state 1 after the minor repair had been implemented. The other transition intensities have the mimic meanings. The corresponding performance level $g_{i s}$ is associated with each component's state $s$.
Because the probability distribution of multi-state component $i$ associated to one state $s$ is a function of time $t$, the index $i$ of one multi-state component has been omitted for the straightforward expression. Such that eq. (3) can be rewritten as:

$$
p_{s}(t)=\operatorname{Pr}\left\{G(t)=g_{s}\right\}, 0 \leq t .
$$

Probabilities $p_{s}(t), s=0,1, \cdots, m$ can be figured out from the solution in the following system of differential equations for the Markov stochastic process of multi-state component:

$$
\frac{d p_{s}(t)}{d t}=\sum_{\substack{i=0 \\ i \neq s}}^{m} p_{i}(t) \alpha_{i s}-p_{s}(t) \sum_{\substack{i=0 \\ i \neq s}}^{m} \alpha_{s i}
$$

where $\alpha_{i s}$ is the transition intensities from state $i$ to state $s$. In this paper all transitions are triggered by the component's minor failures and repairs and so the $\alpha_{i s}$ and $\alpha_{s i}$ is corresponded to the repair rates and failure rates for the state $s$ respectively. Therefore, the corresponding system of differential equations may be unfolded as:

$$
\left\{\begin{aligned}
\frac{d p_{0}(t)}{d t} & =\lambda_{10} p_{1}(t)-u_{01} p_{0}(t) \\
\frac{d p_{1}(t)}{d t} & =\mu_{01} p_{0}(t)+\lambda_{21} p_{2}(t)-\left(u_{12}+\lambda_{10}\right) p_{1}(t) \\
\cdots & =\cdots \\
\frac{d p_{m}(t)}{d t} & =\mu_{m-1, m} p_{m-1}(t)-\lambda_{m, m-1} p_{m}(t)
\end{aligned}\right.
$$

In terms of the reliability meaning, the component's initial state should be in the best performance level, scilicet in the state $m$ at the time $t=0$. So we can reasonably assume that:

$$
\left\{\begin{array}{l}
p_{0}(0)=p_{1}(0)=\cdots=p_{m-1}(0)=0 \\
p_{m}(0)=1
\end{array} .\right.
$$

Wherefore, the multi-state component probabilities distribution $p_{s}(t), s=0,1, \cdots, m$ can be obtained by solving eq. (13) and eq. (14).

\section{Universal generating function technology}

Universal generating function, which is proven to be a very effective method for high-dimension combinatorial problem, is also named as u-function or universal z-transform [16]. Its mathematical fundamental is the extension of the widely known ordinary moment generating function and z-transformation.

The UGF of a multi-state component $i$ with performance level associated with the pmf is defined as a polynomial:

$$
u_{i}(z)=\sum_{h_{i}=0}^{m_{i}} p_{i h_{i}} z^{g_{i h_{i}}}, i=1,2, \cdots, n .
$$

The essential property of UGF enables the entire UGF for a MSS, whose components were connected in series or parallel, to be obtained using simple algebraic operations on individual UGF of multi-state component. To represent the pmf of the stochastic variable $V=\Phi\left(G_{1}, \cdots G_{n}\right)$, the composition operator $\otimes$ is defined by: 


$$
\begin{aligned}
U(z) & =\underset{\phi}{\bigotimes}\left(u_{1}(z), u_{2}(z), \cdots, u_{n}(z)\right)=\underset{\phi}{\bigotimes}\left(\sum_{h_{1}=0}^{m_{1}} p_{1 h_{1}} z^{g_{1 h_{1}}}, \sum_{h_{2}=0}^{m_{2}} p_{2 h_{2}} z^{g_{2 h_{2}}}, \cdots, \sum_{h_{n}=0}^{m_{n}} p_{n h_{n}} z^{g_{n h_{n}}}\right) \\
& =\sum_{h_{1}=0}^{m_{1}} \sum_{h_{2}=0}^{m_{2}} \cdots \sum_{h_{n}=0}^{m_{n}}\left(\prod_{i=1}^{n} p_{i h_{i}} z^{\phi\left(g_{1 h_{1}}, g_{2}, \cdots, g_{n}, \cdots h_{n}\right)}\right)
\end{aligned}
$$

Note that the polynomial $U(z)$ represents all possible mutually exclusive combinations of individual independent component's UGF. The function $\phi\left(g_{1 h_{1}}, g_{2 h_{2}}, \cdots, g_{n h_{n}}\right)$ is determined according to the physical nature of the interaction between component's performances.

Indeed, the derivation of $U(z)$ for various types of systems is a troublesome task usually. As shown in [16], from the computation simplicity and derivation clarity viewpoints representing the $U(z)$ in a recursive form is beneficial. Especially when an MSS has a complex configuration, the entire system can be represented as the composition of some subsystems corresponding to some subsets of multi-state components. This property can be defined by:

$$
\underset{\phi}{\otimes}\left(u_{1}(z), \cdots, u_{k}(z), u_{k+1}(z), \cdots, u_{n}(z)\right)=\underset{\phi}{\bigotimes}\left(\bigotimes_{\phi}\left(u_{1}(z), \cdots, u_{k}(z)\right), \underset{\phi}{\otimes}\left(u_{k+1}(z), \cdots, u_{n}(z)\right)\right)
$$

The configuration of any MSS can always be represented as a composition of independent subsystems containing only components connected in parallel or series. For any components connected in the parallel or in series in the MSS, the composition operator can be applied recursively for obtaining UGF of the intermediate pure parallel or pure series structures.

Considering one type of MSS system, for example power system, energy or materials continuous transmission system, and manufacturing system with its performance level defined as productivity. For components in parallel, the system total productivity is the sum of productivities of all its components. If two independent components ( $i$ and $j$ ) work in parallel, the total productivity is the sum of their individual productivity. The function $\phi_{p}$ should get the sum of corresponding parameters. The performance of the pair of components in this case is defined as:

$$
U_{i j}(z)=u_{i}(z) \otimes u_{j}(z)=\sum_{h_{i}=0}^{m_{i}} \sum_{h_{j}=0}^{m_{j}} p_{i h_{i}} p_{j h_{j}} z^{\operatorname{sum}\left(g_{i h_{i}}, g_{j h_{j}}\right)} .
$$

For components in series, the component with the minimal productivity becomes the system bottleneck. The function $\phi_{S}$ should get the minimum of all parameters. Therefore, the UGF for this case should take this form:

$$
U_{i j}(z)=u_{i}(z) \otimes u_{j}(z)=\sum_{h_{i}=0}^{m_{i}} \sum_{h_{j}=0}^{m_{j}} p_{i h_{i}} p_{j h_{j}} z^{\min \left(g_{i h_{i}}, g_{j h_{j}}\right)} .
$$

\section{MSS reliability evaluation method}

Based on the considerations presented above, the method consisted of Markov stochastic process and UGF can be applied using the following algorithm:

1) Drawing the state-space diagram for the multi-state components of the MSS.

2) Based on the reliability data (failure and repair data, state space) for all the multi-state components in MSS, individual pmf of each component can be obtained by solving the corresponding systems of differential eq. (13) and eq. (14).

3) Having the performance level and corresponding probabilities for each component, the UGF for one component can be written in the form of eq. (15).

4) According to the configuration of system structure, the UGF of the entire MSS can be obtained by applying eq. (17), (18) and (19) recursively:

$$
U(z, t)=\sum_{j=0}^{M_{s y s}} p_{j}^{(s y s)}(t) z^{g_{j}^{(s y s)}}
$$

where $M_{\text {sys }}$ is the state where system has the highest performance level and $g_{j}^{(s y s)}$ is the system performance level in the corresponding state $j, j=0,1, \cdots, M_{\text {sys }}$

5) Calculating reliability indices by the UGF of the entire MSS.

\section{Reliability indices for entire MSS}

When the UGF of the entire MSS has been obtained, the following reliability indices can be evaluated easily.

The entire MSS availability $A(t)$ at instant $t>0$ cab be evaluated as:

$$
A(t)=\delta(U(z, t))=\sum_{j=0}^{M_{s y s}} p_{j}^{(s y s)}(t) \delta\left(g_{j}^{(s y s)}>0\right),
$$

where $\delta($ True $) \equiv 1, \delta($ False $) \equiv 0$.

For a arbitrary constant demand $w$, the MSS availability $A(t, w)$ at instant $t>0$ has the like form:

$$
A(t, w)=\delta(U(z, t), w)=\sum_{j=0}^{M_{\text {sys }}} p_{j}^{(s y s)}(t) \delta\left(g_{j}^{(s y s)} \geq w\right) .
$$

The MSS expected output performance level $E(t)$ at instant $t>0$ is defined as:

$$
E(t)=\delta_{E}(U(z, t))=\delta_{E}\left(\sum_{j=0}^{M_{s y s}} p_{j}^{(s y s)}(t) z^{g_{j}^{(s y s)}}\right)=\sum_{j=0}^{M_{s y s}} p_{j}^{(s y s)}(t) g_{j}^{(s y s)} .
$$

The MSS expected performance deficiency $D(t, w)$ at instant $t>0$ for arbitrary constant demand $w$ is of the form:

$D(t, w)=\delta_{D}(U(z, t), w)=\delta_{D}\left(\sum_{j=0}^{M_{s y s}} p_{j}^{(s y s)}(t) z^{g_{j}^{(s y s)}}, w\right)=\sum_{j=0}^{M_{s y s}} p_{j}^{(s y s)}(t) \max \left(w-g_{j}^{(s y s)}, 0\right)$.

\section{Illustrative examples}

Example 1. A numerical example illustrates the algorithm presented above. Series-parallel structure is often used for the configuration of system as shown in Fig. 2.

This configuration can be seen for example in a flow transmission system whose components are transmission pipe. The steam/oil flow is transmitted from left (A) to right (B) by three pipes denoted 


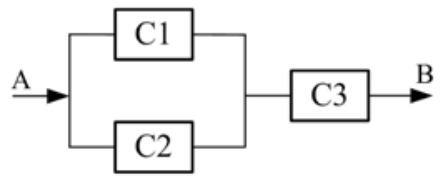

Fig. 2. Series-parallel structure reliability block diagram

as $\mathrm{C} 1, \mathrm{C} 2$ and $\mathrm{C} 3$. The component's performance is measured by its transmission capacity ( $\mathrm{t} / \mathrm{m}$ : tons per minute). Assuming for all the components the times to failure and times to repair are distributed exponentially. $\mathrm{C} 1$ and $\mathrm{C} 2$ are repairable and each has two states: total failure (0) and perfect function (1). C3 is a multi-state component with minor failures and minor repairs. It has three states: total failure (0), partial failure (1) and perfect function (2).

Applying the evaluation method described above, component's state-space transition diagrams are shown firstly in Fig. 3.

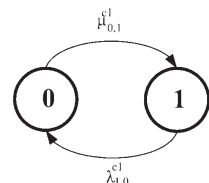

$\mathrm{Cl}$

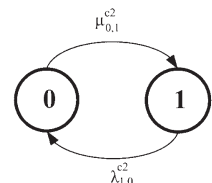

$\mathrm{C} 2$

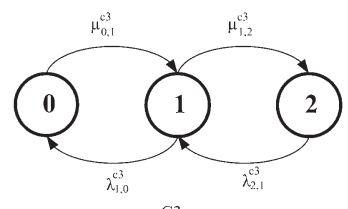

C3
Fig. 3. Component's state-space transmission diagrams

Second, according to the Markov stochastic process, the following systems of differential equations of individual component can be built separately using the corresponding state-space transmission diagram.

The basic reliability data are presented in Table 1 which gives the g, $\lambda$ and $\mu$ of each component.

Table 1. Reliability data for multi-state components

\begin{tabular}{|c|c|c|c|c|}
\hline Component & States & $\begin{array}{l}\text { Performance } \\
(\mathrm{t} / \mathrm{m})\end{array}$ & $\begin{array}{c}\text { Failure rate } \\
\left(\text { year }^{-1}\right)\end{array}$ & $\begin{array}{c}\text { Repair Rate } \\
\quad \text { year }^{-1} \text { ) }\end{array}$ \\
\hline i & $j$ & $g_{j}^{i}$ & $\lambda_{j, j-1}^{i}$ & $\mu_{j, j+1}^{i}$ \\
\hline \multirow[t]{2}{*}{$\mathrm{C} 1$} & 0 & 0 & - & 100 \\
\hline & 1 & 1.5 & 7 & - \\
\hline \multirow[t]{2}{*}{ C2 } & 0 & 0 & - & 80 \\
\hline & 1 & 2 & 10 & - \\
\hline \multirow[t]{3}{*}{$\mathrm{C} 3$} & 0 & 0 & - & 120 \\
\hline & 1 & 1.8 & 7 & 110 \\
\hline & 2 & 4 & 10 & - \\
\hline
\end{tabular}

For $\mathrm{C} 1$, one can obtain:

$$
\left\{\begin{array}{l}
\frac{d p_{0}^{c 1}(t)}{d t}=\lambda_{10}^{c 1} p_{1}^{c 1}(t)-u_{01}^{c 1} p_{0}^{c 1}(t) \\
\frac{d p_{1}^{c 1}(t)}{d t}=-\lambda_{10}^{c 1} p_{1}^{c 1}(t)+u_{01}^{c 1} p_{0}^{c 1}(t)
\end{array},\right.
$$

where the initial parameters are $p_{0}^{c 1}(0)=0, p_{1}^{c 1}(0)=1$.

For $\mathrm{C} 2$, its differential equations are:

$$
\left\{\begin{array}{l}
\frac{d p_{0}^{c 2}(t)}{d t}=\lambda_{10}^{c 2} p_{1}^{c 2}(t)-u_{01}^{c 2} p_{0}^{c 2}(t) \\
\frac{d p_{1}^{c 2}(t)}{d t}=-\lambda_{10}^{c 2} p_{1}^{c 2}(t)+u_{01}^{c 2} p_{0}^{c 2}(t)
\end{array},\right.
$$

likewise the initial conditions are $p_{0}^{c 2}(0)=0, p_{1}^{c 2}(0)=1$.

For $\mathrm{C} 3$, we can also get its state differential equations

$$
\left\{\begin{array}{l}
\frac{d p_{0}^{c 3}(t)}{d t}=\lambda_{10}^{c 3} p_{1}^{c 3}(t)-u_{01}^{c 3} p_{0}^{c 3}(t) \\
\frac{d p_{1}^{c 3}(t)}{d t}=\lambda_{21}^{c 3} p_{2}^{c 3}(t)+u_{01}^{c 3} p_{0}^{c 3}(t)-\left(\lambda_{10}^{c 3}+u_{12}^{c 3}\right) p_{1}^{c 3}(t), \\
\frac{d p_{2}^{c 3}(t)}{d t}=-\lambda_{21}^{c 3} p_{2}^{c 3}(t)+u_{12}^{c 3} p_{1}^{c 3}(t)
\end{array}\right.
$$

where the initial conditions are $p_{0}^{c 3}(0)=p_{1}^{c 3}(0)=0, p_{2}^{c 3}(0)=1$.

According to the property of Laplace transform, the closed form solutions of $\mathbf{p}^{c 1}(t), \mathbf{p}^{c 2}(t), \mathbf{p}^{c 3}(t)$ can be obtained from eq. (25), (26) and (27).

Third, the UGF of the individual component can be obtained combining the performance level and corresponding probability distribution:

$\left\{\begin{array}{l}u_{1}(z)=p_{0}^{c 1}(t) z^{c_{0}^{c 1}}+p_{1}^{c 1}(t) z^{g_{1}^{c 1}}=p_{0}^{c 1}(t) z^{0}+p_{1}^{c 1}(t) z^{1.5} \\ u_{2}(z)=p_{0}^{c 2}(t) z^{g_{0}^{c 2}}+p_{1}^{c 2}(t) z^{g_{1}^{c 2}}=p_{0}^{c 2}(t) z^{0}+p_{1}^{c 2}(t) z^{2} \\ u_{3}(z)=p_{0}^{c 3}(t) z^{g_{0}^{c 3}}+p_{1}^{c 3}(t) z^{g_{1}^{c 3}}+p_{2}^{c 3}(t) z^{c_{2}^{c 3}}=p_{0}^{c 3}(t) z^{0}+p_{1}^{c 3}(t) z^{1.8}+p_{2}^{c 3}(t) z^{4}\end{array}\right.$

Fourth, according to the configuration of components, the UGF of subsystem sub12 consisted of $\mathrm{C} 1$ and $\mathrm{C} 2$ connected in parallel can be obtained using eq. (18):

$$
\begin{aligned}
U_{s u b 12}(z) & =u_{1}(z) \underset{\phi_{p}}{\otimes} u_{2}(z)=\left(p_{0}^{c 1}(t) z^{0}+p_{1}^{c 1}(t) z^{1.5}\right) \underset{\phi_{p}}{\otimes}\left(p_{0}^{c 2}(t) z^{0}+p_{1}^{c 2}(t) z^{2}\right) \\
& =p_{0}^{c 1}(t) p_{0}^{c 2}(t) z^{0}+p_{1}^{c 1}(t) p_{0}^{c 2}(t) z^{1.5}+p_{0}^{c 1}(t) p_{1}^{c 2}(t) z^{2}+p_{1}^{c 1}(t) p_{1}^{c 2}(t) z^{3.5}
\end{aligned}
$$

As can be found the resulting of $U_{s u b 12}$ is actually the algebraic product of $u_{1}(z)$ and $u_{2}(z)$.Then the entire MSS can be seen as a series connected sub12 and $\mathrm{C} 3$, the eq. (19) should be espoused to solve the UGF of the system:

$$
U(z)=U_{s u b 12}(z) \underset{\phi_{s}}{\otimes} u_{3}(z) .
$$

In addition to the same point that the resulting UGF $U(z)$ is also a product of polynomials, what is in difference with function $\phi_{p}$ is that function $\phi_{s}$ deals with the powers of $z$ as the minimum of powers of the corresponding terms. Taking into account that:

$$
\left\{\begin{array}{l}
p_{0}^{c 1}(t)+p_{1}^{c 1}(t)=1 \\
p_{0}^{c 2}(t)+p_{1}^{c 2}(t)=1 \\
p_{0}^{c 3}(t)+p_{1}^{c 3}(t)+p_{2}^{c 3}(t)=1
\end{array},\right.
$$
form:

The UGF of the total MSS can be obtained in the following 


$$
U(z)=\sum_{i=0}^{4} p_{i}(t) z^{g_{i}}
$$

where:

$$
\begin{gathered}
\mathbf{g}=\left(g_{0}, g_{1}, g_{2}, g_{3}, g_{4}\right)=(0,1.5,1.8,2.0,3.5) \\
\mathbf{p}=\left(\begin{array}{l}
p_{0}(t) \\
p_{1}(t) \\
p_{2}(t) \\
p_{3}(t) \\
p_{4}(t)
\end{array}\right)=\left(\begin{array}{l}
p_{0}^{c 1}(t) p_{0}^{c 2}(t)+p_{0}^{c 1}(t) p_{1}^{c 2}(t) p_{0}^{c 3}(t)+p_{1}^{c 1}(t) p_{0}^{c 3}(t) \\
p_{1}^{c 1}(t) p_{0}^{c 2}(t)\left(p_{1}^{c 3}(t)+p_{2}^{c 3}(t)\right) \\
p_{1}^{c 2}(t) p_{1}^{c 3}(t) \\
p_{0}^{c 1}(t) p_{1}^{c 2}(t) p_{2}^{c 3}(t) \\
p_{1}^{c 1}(t) p_{1}^{c 2}(t) p_{2}^{c 3}(t)
\end{array}\right)
\end{gathered}
$$

Finally, the MSS reliability indices can be calculated respectively by using eq. (21), (22), (23) and (24) based on the UGF of the entire MSS.

The instantaneous MSS availability $A(t)$ at $t>0$ :

$$
A(t)=\delta(U(z, t))=\sum_{j=0}^{4} p_{j}(t) \delta\left(g_{j}>0\right)=\sum_{j=1}^{4} p_{j}(t)=1-p_{0}(t) .
$$

For a arbitrary constant demand $w=2.0 t / m$, the MSS availability $A(t, w)$ at instant $t>0$ :

$$
A(t, w)=\sum_{j=0}^{4} p_{j}(t) \delta\left(g_{j} \geq 2\right)=p_{3}(t)+p_{4}(t) .
$$

The MSS expected output performance level $E(t)$ at instant $t>0$ :

$$
E(t)=\delta_{E}(U(z, t))=\sum_{j=0}^{4} p_{j}(t) g_{j}
$$

The MSS expected performance deficiency $D(t, w)$ at instant $t>0$ for arbitrary constant demand $w=2.0 t / m$ :

$$
D(t, w)=\sum_{j=0}^{4} p_{j}(t) \max \left(2-g_{j}, 0\right)=2 p_{0}(t)+0.5 p_{1}(t)+0.2 p_{2}(t)
$$

From the above we can find that the MSS mentioned will be of $2 * 2 * 3=12$ differential equations if the straightforward Markov stochastic method were performed. Consequently the computational efforts will be consumed numerously. However the presented combined approach needs only to solve three differential equations of component: two of second-order and one of third-order. The further derivation of the MSS state probabilities and reliability indices is based on the UGF which can be implemented by simple mathematical calculation.

Example 2. A more realistic system can be adopted to validate its applicability and effectiveness of the new approach. The system is a power station coal feeding system supplying a boiler with coal. It consists of five basic subsystems as shown in Fig. 4 [43].

The function of each subsystem can be described as following. The subsystem 1 is the primary feeder which loads the coal from the bin to the primary conveyor. The primary conveyor can be seen as the subsystem 2 which transports the coal to the stacker-reclaimer. The subsystem 3 is the stacker-reclaimer which lifts the coal up to the burner level. The secondary feeder is the subsystem 4 which loads

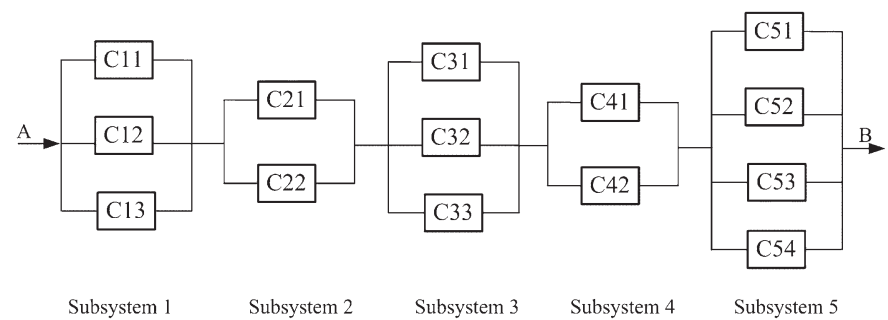

Fig. 4. Reliability block diagram of the coal feeding system with five subsystems

the secondary conveyor. The subsystem 5 is the secondary conveyor which supplies the burner feeding system of the boiler [29]. The elements in subsystem 1, 3 and 4 have four states corresponding to their performance level. The subsystem 2 consists of two three-state elements while the subsystem 5 consists of four elements with five states. Generally speaking, we can assume that each subsystem con-

\begin{tabular}{|c|c|c|c|c|}
\hline Component & States & $\begin{array}{l}\text { Performance } \\
\text { (ton/day) }\end{array}$ & $\begin{array}{c}\text { Failure rate } \\
\left(\text { year }^{-1} \text { ) }\right.\end{array}$ & $\begin{array}{c}\text { Repair Rate } \\
\left(\text { year }^{-1}\right)\end{array}$ \\
\hline $\mathrm{i}$ & $j$ & $g_{j}^{i}$ & $\lambda_{j, j-1}^{i}$ & $\mu_{j, j+1}^{i}$ \\
\hline \multirow[t]{4}{*}{$\mathrm{C} 11$} & 0 & 0 & - & 2 \\
\hline & 1 & 40 & 0.5 & 2 \\
\hline & 2 & 60 & 0.3 & 2 \\
\hline & 3 & 80 & 0.2 & - \\
\hline \multirow[t]{3}{*}{$\mathrm{C} 21$} & 0 & 0 & - & 3 \\
\hline & 1 & 70 & 0.5 & 3 \\
\hline & 2 & 120 & 0.2 & - \\
\hline
\end{tabular}
sists of the same type of component respectively. The state transition intensities and state performance rate of each component extracted from [42] are tabulated in Table 2. For the purpose of terseness, the first component of subsystem 1 and subsystem 2 are only listed and we will only discuss the series of subsystem 1 and subsystem 2 .

Table 2. The basic data of each type component

Here, we omit the steps, which are similar to the first example, to solve the state probability distribution of each multistate component. The state probability of each component can be written as $\mathbf{P}^{C 11}(t)=\left(p_{0}^{C 11}(t), p_{1}^{C 11}(t), p_{2}^{C 11}(t), p_{3}^{C 11}(t)\right) \quad$ and $\mathbf{P}^{C 21}(t)=\left(p_{0}^{C 21}(t), p_{1}^{C 21}(t), p_{2}^{C 21}(t)\right)$. The UGF of component $\mathrm{C} 11$ and $\mathrm{C} 21$ will be obtained as:

$$
\left\{\begin{array}{l}
U_{C 11}=p_{0}^{C 11}(t) * z^{0}+p_{1}^{C 11}(t) * z^{40}+p_{2}^{C 11}(t) * z^{60}+p_{3}^{C 11}(t) * z^{80} \\
U_{C 21}=p_{0}^{C 21}(t) * z^{0}+p_{1}^{C 21}(t) * z^{70}+p_{2}^{C 21}(t) * z^{120}
\end{array}\right.
$$

Because the type of component within subsystem 1 is same, such that $U_{C 11}=U_{C 12}=U_{C 13}=U_{C 14}$. According to eq. (18), the UGF of the subsystem 1 will be rewritten as:

$$
U_{s u b s 1}=\underset{\phi_{p}}{U_{C 11} \otimes \phi_{p}} \underset{\phi_{p}}{U} \underset{C 13}{\Theta}
$$


When $t=0.5$ year, the probability distribution of each state for each component of subsystem 1 will be same as $\mathbf{P}^{C 11}(0.5)=(0.0004,0.0055,0.0894,0.9407)$. Substituting the $\mathbf{P}^{C 11}(0.5)$ into the above equation, the eq. (40) can be expressed as:

$U_{\text {subs } 1}=0.2560 \mathrm{e}-13^{*} \mathrm{z}^{0}+0.1408 \mathrm{e}-11{ }^{*} \mathrm{z}^{40}+0.2289 \mathrm{e}-10^{*} \mathrm{z}^{60}+0.2606 \mathrm{e}-9^{*} \mathrm{z}^{80}+0.9441 \mathrm{e}-9 * \mathrm{z}^{100}+$ $0.1749 \mathrm{e}-7 * \mathrm{z}^{120}+0.1683 \mathrm{e}-6^{*} \mathrm{z}^{140}+0.1129 \mathrm{e}-5^{*} \mathrm{z}^{160}+0.5473 \mathrm{e}-5^{*} \mathrm{z}^{180}+0.5837 \mathrm{e}-4^{*} \mathrm{z}^{200}+$ $0.3963 \mathrm{e}-3 * \mathrm{z}^{220}+0.1874 \mathrm{e}-2 * \mathrm{z}^{240}+0.7415 \mathrm{e}-2 * \mathrm{z}^{260}+0.5554 \mathrm{e}-1 * \mathrm{z}^{280}+0.2648 * \mathrm{z}^{300}+0.6699 * \mathrm{z}^{320}$

From the above formula, it can be found that the probability transporting performance less 200 ton/day for subsystem 1 at the time 0.5 year is less 0.0001 and almost can be neglected.

In the same way, the probability for each component of subsystem 2 can be figured outas $\mathbf{P}^{C 21}(0.5)=\mathbf{P}^{C 22}(0.5)=(0.0047,0.0477,0.9476)$.

Combining the probability with the operator $\otimes$, the UGF of the subsystem 2 will be written as: $\phi_{p}$

$$
\begin{aligned}
U_{\text {subs } 2} & =0.2209 \mathrm{e}-4 * \mathrm{z}^{0}+0.4484 \mathrm{e}-3 * \mathrm{z}^{70}+0.8907 \mathrm{e}-2 * \mathrm{z}^{120} \\
& +0.2275 \mathrm{e}-2 * \mathrm{z}^{140}+0.9040 \mathrm{e}-1 * \mathrm{z}^{190}+0.8979 * \mathrm{z}^{240}
\end{aligned}
$$

In order to calculate the probability distribution of the series structure of subsystem 1 and subsystem 2 at $t=0.5$ year, we tabulate their state/performance probability distribution in the Table 3. Among all the states, those states whose probability is very little are ignored.
Denoted the series structure of subsystem 1 and subsystem 2 by $S_{\text {sub1,sub2 }}$, according to the operator $\otimes$, the state/performance and

corresponding probability can be shown in the last two columns of the above table. Furthermore, we can calculate the relevant reliability indices. For example, given a constant demand $w=200$, we have $A_{S_{\text {sub1,sub2 }}}(0.5,200)=0.897864$ and the expect of output performance $E_{S_{\text {sub1,sub2 }}}(0.5)=234.043$. In this way, we can obtain state/performance probability distribution of the whole system and calculate other reliability indices.

When the combination method is adopted directly, the state space of the series of subsystem 1 and subsystem 2 can reach $4^{4} * 3^{3}=6912$. However, the realistic result based on the analyzing mentioned above will be reduced to only six because many duplicated or little probability states can be cut or omitted by using the UGF technology. These justify the combined method put forward in this paper.

\section{Conclusoin}

In this paper an important type of repairable MSS that does not existed in traditional binary-state systems has been considered. Mathematical models based on straightforward Markov process are usually not effective enough for engineering application because of huge number of system states. A new combined method to evaluate the reliability indices of MSS with minor failure and minor repair is suggested. The method is based on the combination of the Markov stochastic process and the UGF technology. Furthermore, multi-state models for system components have been taken into account.

The method is highly suitable for engineering applications because the procedure is well formalized and based on the natural decomposition of the entire MSS. By using this method, the process for modeling of the MSS and solving of system differential equations has been greatly simplified. The performance levels and reliability indices of MSS can be calculated accurately.

Table 3. state/performance probability distribution of subsystem 1, subsystem 2 and their series at $t=0.5$ year
\begin{tabular}{|c|c|c|c|c|c||}
\hline \multicolumn{2}{|c|}{ Subsystem 1 } & \multicolumn{2}{c|}{ Subsystem 2 } & \multicolumn{2}{c||}{$S_{\text {subl,sub } 2}$} \\
\hline $\begin{array}{c}\text { State/Performance } \\
\text { (ton/day) }\end{array}$ & Probability & $\begin{array}{c}\text { State/Performance } \\
\text { (ton/day) }\end{array}$ & Probability & $\begin{array}{c}\text { State/Performance } \\
\text { (ton/day) }\end{array}$ & Probability \\
\hline 320 & 0.6699 & - & - & - & - \\
\hline 300 & 0.2648 & - & - & - & - \\
\hline 280 & 0.0555 & - & - & 240 & 0.897451 \\
\hline 260 & 0.0074 & 240 & 0.8979 & 220 & 0.000359 \\
\hline 240 & 0.0019 & 190 & 0.0904 & 200 & 0.000054 \\
\hline 220 & 0.0004 & 140 & 0.0023 & 190 & 0.090396 \\
\hline 200 & 0.00006 & 120 & 0.0089 & 140 & 0.002299 \\
\hline$<200$ & 0.00004 & $\leq 70$ & 0.0005 & 120 & 0.008899 \\
\hline
\end{tabular}

\section{Acknowledgment:}

The authors wish to thank the reviewers and the Editor for their constructive comments that have helped to improve the article. This work was supported in part by a grant from Key Program of National Nature Science Foundation of China (51036002), National Basic Research Program of China (973 Program) (2012CB215203), Hebei Province Natural Science Foundation (F2014502081) and Fundamental Research Funds for the Central Universities (No. 2014MS165, No. 2015MS128, No. 2015MS139).

\section{References}

1. Anatoly, L. and F. Ilia. Recent Advances in System Reliability. London, Springer-Verlag, 2012.

2. Anatoly Lisnianski, D. E., David Laredo, Hanoch Ben Haim. A multi-state Markov model for a short-term reliability analysis of a power generating unit. Reliability Engineering and System Safety 2012; 98(1): 1-6, http://dx.doi.org/10.1016/j.ress.2011.10.008.

3. Aven, T. and U. Jensen. Stochastic Models in Reliability. New York, Springer-Verlag, 1999. http://dx.doi.org/10.1007/b97596

4. Barlow, R. E. Mathematical reliability theory: from the beginning to the present time 2002; World Scientific. 
5. Barlow, R. E. Mathematical theory of reliability: A historical perspective. Reliability, IEEE Transactions on 1984; R-33(1): 16-20, http:// dx.doi.org/10.1109/tr.1984.6448269.

6. Barlow, R. E. and F. Proschan. Mathematical theory of reliability. New York, Wiley, 1965.

7. Barlow, R. E. and A. S. Wu. Coherent Systems with Multi-State Components. Mathematics of Operations Research 1978; 3(4): $275-281$. http://dx.doi.org/10.1287/moor.3.4.275

8. Chang, P. C. and Y. K. Lin. Fuzzy-based system reliability of a labour-intensive manufacturing network with repair. International Journal of Production Research 2015; 53(7): 1980-1995, http://dx.doi.org/10.1080/00207543.2014.944279.

9. Di Maio, F., D. Colli, E. Zio, L. Tao and J. Tong. A Multi-State Physics Modeling approach for the reliability assessment of Nuclear Power Plants piping systems. Annals of Nuclear Energy 2015; 80: 151-165, http://dx.doi.org/10.1016/j.anucene.2015.02.007.

10. Ding, Y. and A. Lisnianski. Fuzzy universal generating functions for multi-state system reliability assessment. Fuzzy Sets and Systems 2008; 159(3): 307-324, http://dx.doi.org/10.1016/j.fss.2007.06.004.

11. Doostparast, M., F. Kolahan and M. Doostparast. A reliability-based approach to optimize preventive maintenance scheduling for coherent systems. Reliability Engineering \& System Safety 2014; 126(0): 98-106, http://dx.doi.org/10.1016/j.ress.2014.01.010.

12. Gandini, A. Importance and sensitivity analysis in assessing system reliability. Reliability, IEEE Transactions on 1990; 39(1): 61-70, http:// dx.doi.org/10.1109/24.52613.

13. Guilani, P. P., M. Sharifi, S. T. A. Niaki and A. Zaretalab. Reliability evaluation of non-reparable three-state systems using Markov model and its comparison with the UGF and the recursive methods. Reliability Engineering \& System Safety 2014; 129: 29-35, http://dx.doi. org/10.1016/j.ress.2014.04.019.

14. Janan, X. On Multistate System Analysis. Reliability, IEEE Transactions on 1985; R-34(4): 329-337.

15. Levitin, G. Block diagram method for analyzing multi-state systems with uncovered failures. Reliability Engineering \& System Safety 2007; 92(6): 727-734, http://dx.doi.org/10.1016/j.ress.2006.02.009.

16. Levitin, G. The universal generating function in reliability analysis and optimization. London, Springer-Verlag, 2005.

17. Levitin, G. and A. Lisnianski. Joint redundancy and maintenance optimization for multistate series-parallel systems. Reliability Engineering \& System Safety 1999; 64(1): 33-42, http://dx.doi.org/10.1016/S0951-8320(98)00052-0.

18. Levitin, G., A. Lisnianski, H. Ben-Haim and D. Elmakis. Redundancy optimization for series-parallel multi-state systems. Reliability, IEEE Transactions on 1998; 47(2): 165-172, http://dx.doi.org/10.1109/24.722283.

19. Levitin, G., L. Xing, H. Ben-Haim and Y. Dai. Multi-state systems with selective propagated failures and imperfect individual and group protections. Reliability Engineering \& System Safety 2011; 96(12): 1657-1666, http://dx.doi.org/10.1016/j.ress.2011.08.002.

20. Levitin, G., L. Xing, H. Ben-Haim and Y. Dai. Reliability of Series-Parallel Systems With Random Failure Propagation Time. Ieee Transactions on Reliability 2013; 62(3): 637-647, http://dx.doi.org/10.1109/TR.2013.2270415.

21. Li, C.-y., X. Chen, X.-s. Yi and J.-y. Tao. Heterogeneous redundancy optimization for multi-state series-parallel systems subject to common cause failures. Reliability Engineering \& System Safety 2010; 95(3): 202-207, http://dx.doi.org/10.1016/j.ress.2009.09.011.

22. Li, W. and M. J. Zuo. Reliability evaluation of multi-state weighted k-out-of-n systems. Reliability Engineering \& System Safety 2008; 93(1): 160-167, http://dx.doi.org/10.1016/j.ress.2006.11.009.

23. Lin, Y.-K. and C.-F. Huang. Reliability Evaluation of a Multi-state Network with Multiple Sinks under Individual Accuracy Rate Constraint. Communications in Statistics-Theory and Methods 2014; 43(21): 4519-4533, http://dx.doi.org/10.1080/03610926.2012.716137.

24. Lisnianski, A. and Y. Ding. Redundancy analysis for repairable multi-state system by using combined stochastic processes methods and universal generating function technique. Reliability Engineering \& System Safety 2009; 94(11): 1788-1795, http://dx.doi.org/10.1016/j. ress.2009.05.006.

25. Lisnianski, A., G. Levitin and H. Ben-Haim. Structure optimization of multi-state system with time redundancy. Reliability Engineering \& System Safety 2000; 67(2): 103-112, http://dx.doi.org/10.1016/S0951-8320(99)00049-6.

26. Ming Tan, C. and N. Raghavan. A framework to practical predictive maintenance modeling for multi-state systems. Reliability Engineering \& System Safety 2008; 93(8): 1138-1150, http://dx.doi.org/10.1016/j.ress.2007.09.003.

27. Mo, Y. C., L. D. Xing, S. V. Amari and J. B. Dugan. Efficient analysis of multi-state k-out-of-n systems. Reliability Engineering \& System Safety 2015; 133: 95-105, http://dx.doi.org/10.1016/j.ress.2014.09.006.

28. Nahas, N., A. Khatab, D. Ait-Kadi and M. Nourelfath. Extended great deluge algorithm for the imperfect preventive maintenance optimization of multi-state systems. Reliability Engineering \& System Safety 2008; 93(11): 1658-1672, http://dx.doi.org/10.1016/j.ress.2008.01.006.

29. Nourelfath, M. and D. Ait-Kadi. Optimization of series-parallel multi-state systems under maintenance policies. Reliability Engineering \& System Safety 2007; 92(12): 1620-1626, http://dx.doi.org/10.1016/j.ress.2006.09.016.

30. Pandey, M., M. J. Zuo and R. Moghaddass. Selective maintenance modeling for a multistate system with multistate components under imperfect maintenance. IIE Transactions 2013; 45(11): 1221-1234, http://dx.doi.org/10.1080/0740817X.2012.761371.

31. Parikh, C. R., M. J. Pont and N. Barrie Jones. Application of Dempster"CShafer theory in condition monitoring applications: a case study. Pattern Recognition Letters 2001; 22(6): 777-785, http://dx.doi.org/10.1016/S0167-8655(01)00014-9.

32. Rami, A., H. Hamdaoui, H. Sayah and A. Zeblah. Efficient harmony search optimization for preventive-maintenance-planning for nuclear power systems. International Journal for Simulation and Multidisciplinary Design Optimization 2014; 5: A17, http://dx.doi.org/10.1051/ smdo/2013011.

33. Rueda, A. and M. Pawlak. Pioneers of the reliability theories of the past 50 years. Reliability and Maintainability, 2004 Annual Symposium - RAMS 2004; 102-109, http://dx.doi.org/10.1109/rams.2004.1285431.

34. Tian, Z., G. Levitin and M. J. Zuo. A joint reliability-redundancy optimization approach for multi-state series-parallel systems. Reliability Engineering \& System Safety 2009; 94(10): 1568-1576, http://dx.doi.org/10.1016/j.ress.2009.02.021.

35. Ushakov. "Reliability: past, present, future," Recent Advances in Reliability Theory: Methodology, Practice, and Interface,. Boston, Birkhäuser, 2000.

36. Ushakov, I. Optimal standby problems and a universal generating function. Soviet journal of computer and systems sciences 1987; 25(4): 79-82.

37. Wang, L., X. Jia and J. Zhang. Reliability Evaluation for Multi-State Markov Repairable Systems with Redundant Dependencies. Quality Technology and Quantitative Management 2013; 10(3): 277-289. 
38. Xiao, H. and R. Peng. Optimal allocation and maintenance of multi-state elements in series-parallel systems with common bus performance sharing. Computers \& Industrial Engineering 2014; 72(0): 143-151, http://dx.doi.org/10.1016/j.cie.2014.03.014.

39. Yeh, W.-C. Evaluation of all one-to-many reliabilities for acyclic multistate-node distributed computing system under cost and capacity constraints. Computer Communications 2007; 30(18): 3796-3806, http://dx.doi.org/10.1016/j.comcom.2007.09.005.

40. Yeh, W. C. A novel node-based sequential implicit enumeration method for finding all d-MPs in a multistate flow network. Information Sciences 2015; 297: 283-292, http://dx.doi.org/10.1016/j.ins.2014.11.007.

41. Yu, L. and H. Hong-Zhong. Optimal Selective Maintenance Strategy for Multi-State Systems Under Imperfect Maintenance. Reliability, IEEE Transactions on 2010; 59(2): 356-367, http://dx.doi.org/10.1109/TR.2010.2046798.

42. Yu, L. and H. Hong-Zhong. Optimization of multi-state elements replacement policy for multi-state systems. Reliability and Maintainability Symposium (RAMS), 2010 Proceedings - Annual 2010; 1-7.

43. Zhou, Y., T. R. Lin, Y. Sun, Y. Bian and L. Ma. An effective approach to reducing strategy space for maintenance optimisation of multistate series-parallel systems. Reliability Engineering \& System Safety 2015; 138(0): 40-53, http://dx.doi.org/10.1016/j.ress.2015.01.018.

44. Zio, E. Reliability engineering: Old problems and new challenges. Reliability Engineering \& System Safety 2009; 94(2): 125-141, http:// dx.doi.org/10.1016/j.ress.2008.06.002.

45. Zio, E., M. Marella and L. Podofillini. A Monte Carlo simulation approach to the availability assessment of multi-state systems with operational dependencies. Reliability Engineering \& System Safety 2007; 92(7): 871-882, http://dx.doi.org/10.1016/j.ress.2006.04.024.

\author{
Jinlei QIN \\ Information and Network Management Center \\ North China Electric Power University \\ Baoding, 071003, China
}

Yuguang NIU

State Key Laboratory of Alternate Electric Power System

with Renewable Energy Sources

North China Electric Power University

Beijing, 102206, China

\title{
Zheng LI
}

Department of Computer Science and Technology

North China Electric Power University

Baoding, 071003, China

Email: jlqin717@163.com,nyg@ncepu.edu.cn, yeziperfect@163.com 